\title{
Pelatihan penyusunan artikel ilmiah bagi guru sekolah dasar di Kecamatan Marpoyan Damai Pekanbaru
}

\author{
Dea Mustika ${ }^{1 *}$, Siti Quratul Ain ${ }^{1}$, Agna Dewi Iranti ${ }^{1}$ \\ ${ }^{1}$ Prodi PGSD, FKIP, Universitas Islam Riau, Pekanbaru \\ deamustika@edu.uir.ac.id
}

\begin{abstract}
This activity is motivated by the lack of understanding and ability of elementary school teachers in the preparation of scientific articles. Many teachers are still reluctant to publish research results on the grounds that they do not understand the guidelines for preparing scientific articles. This is what underlies the need to carry out this service activity with the aim of helping elementary school teachers in compiling scientific articles so that later teachers can publish articles that have been made in journals or mass media. Community service activities were carried out in January 2020 at the SDN 193 Pekanbaru teacher council room. The method used is divided into two stages, namely the delivery of material and assistance for teachers who want to compile scientific articles according to their reports. With this service activity, it can provide new concepts of knowledge for teachers so that they can compile scientific articles, especially from the results of research that has been done.
\end{abstract}

Keywords: article writing; scientific article; elementary school teacher

\begin{abstract}
Abstrak
Kegiatan pengabdian kepada masyarakat ini dilatarbelakangi oleh masih kurangnya pemahaman dan kemampuan guru sekolah dasar dalam penyusunan artikel ilmiah. Banyak guru yang masih enggan mempublikasikan hasil penelitian dengan alasan tidak paham dengan pedoman penyusunan artikel ilmiah. Hal inilah yang mendasari perlunya dilakukan kegiatan pengabdian ini dengan tujuan untuk membantu guru sekolah dasar dalam menyusun artikel ilmiah sehingga nantinya guru dapat mempublikasikan artikel yang telah dibuat pada jurnal ataupun media massa. Kegiatan pengabdian dilaksanakan pada bulan Januari 2020 bertempat di ruang majelis guru SDN 193 Pekanbaru. Metode yang digunakan dibagi atas dua tahapan yang berupa penyampaian materi dan pendampingan bagi guru yang ingin menyusun artikel ilmiah sesuai laporan yang dimiliki. Dengan adanya kegiatan pengabdian ini dapat memberi konsep pengetahuan baru bagi guru agar dapat menyusun artikel ilmiah terutama dari hasil penelitian yang telah dilakukan.
\end{abstract}

Kata Kunci: artikel ilmiah; penulisan artikel; guru sekolah dasar

\section{PENDAHULUAN}

Guru sebagai pendidik profesional dituntut untuk mampu mengembangkan ilmu pengetahuan. Sesuai dengan Permendiknas No 16 Tahun 2007 yang menyatakan bahwa standar kualifikasi akademik dan standar kompetensi guru terdiri dari kompetensi pedagogik, kompetensi kepribadian, kompetensi sosial dan kompetensi profesional. Artinya guru diminta untuk mengembangkan ilmu pengetahuan dengan berbagai cara. 
Ilmu tidak akan dapat berkembang optimal jika hanya dilakukan dengan cara berpikir saja, perlu diupayakan suatu usaha untuk menuangkan setiap ide, gagasan dan pemikiran yang ada salah satunya dalam bentuk tulisan. Kemampuan menyusun atau merancang tulisan ini juga menjadi kemampuan yang dituntut harus dimiliki oleh seorang guru profesional. Kemampuan menulis menjadi bagian pengembangan karir bagi guru dan sarana pengembangan diri bagi guru (Prabawati \& Muslim, 2020). Dengan adanya kemampuan menulis, guru dapat menguraikan berbagai data dan permasalahan yang ada di lingkungan pendidikan serta berupaya untuk mencarikan solusinya (Setianingsih et al., 2020; Suyono et al., 2021). Tulisan yang dihasilkan oleh guru juga dapat menjadi suatu upaya dalam memahami berbagai fenomena pembelajaran yang ada di lingkungan sekolah.

Kemampuan menulis yang harus dilatih pada diri seorang guru salah satunya adalah dalam penulisan karya ilmiah. Karya ilmiah merupakan pengembangan karir guru yang mengarah pada pengembangan profesional (Nurgiansah, 2020). Alasan yang mendasari guru dapat mengembangkan diri melalui kegiatan menulis karya ilmiah adalah dikarenakan kondisi guru yang selalu berinteraksi dengan ilmu pengetahuan, siswa, ataupun dunia pendidikan secara umum yang dapat dijadikan sebagai bahan tulisan (Gunawan, 2014; Hidayah et al., 2020). Peluang kompetisi seperti lomba dan publikasi di media massa yang masih banyak tersedia menjadikan tidak ada alasan bagi guru untuk tidak mau mengembangkan diri melalui penulisan karya ilmiah. Budaya copy paste yang selama ini menjadi penyebab kurangnya motivasi dalam menulis ide dan gagasan harus segera diatasi terutama dalam penulisan karya ilmiah (Arta, 2019; Cahyo et al., 2021; Ismail \& Elihami, 2019). Salah satu penulisan karya ilmiah yang bisa dilatih oleh guru untuk dipelajari adalah penulisan artikel ilmiah.

Artikel ilmiah merupakan satu bentuk karya ilmiah yang ditulis dengan berdasarkan pada sebuah pedoman atau tata cara penulisan ilmiah sehingga dapat dipertanggungjawabkan (Annisa \& Hamid, 2016). Tujuan dari artikel ilmiah adalah supaya tulisan yang telah disusun dapat dipublikasikan dalam jurnal ataupun media massa dengan pedoman yang ditentukan (Abdillah, 2012; Yanti et al., 2020). Analisis dilapangan setelah melakukan wawancara dengan beberapa guru didapatkan informasi bahwasanya sebagian besar guru belum memahami tentang konsep artikel ilmiah dengan baik. Sebagian besar guru banyak yang belum pernah melakukan publikasi walaupun sudah mempunyai bahan penelitian berupa PTK untuk dijadikan sebagai artikel ilmiah. Seringkali laporan penelitian yang telah dirancang oleh guru hanya berakhir dalam bentuk laporan dan tidak dikembangkan lebih lanjut (Benardi \& Putro, 2019; Prabawati \& Muslim, 2020).

Berdasarkan hal inilah, dosen-dosen dari jurusan Pendidikan Guru Sekolah Dasar, Fakultas Keguruan dan Ilmu Pendidikan, Universitas Islam Riau (PGSD FKIP UIR) melakukan kegiatan pengabdian dengan tujuan memberi pelatihan penyusunan artikel ilmiah bagi guru sekolah dasar di kecamatan Marpoyan Damai, Pekanbaru. Kegiatan ini dimaksudkan untuk meningkatkan pengetahuan dan pemahaman guru dalam 
penyusunan artikel ilmiah, serta mendorong guru untuk mampu membuat sebuah rancangan artikel ilmiah yang siap untuk dipublikasikan.

\section{METODE PELAKSANAAN}

Kegiatan pengabdian kepada masyarakat dilaksanakan di SD Negeri 193 Kecamatan Marpoyan Damai Kota Pekanbaru. Pelaksanaan kegiatan dimulai pada bulan Oktober 2019 hingga dengan bulan Januari 2020. Kegiatan dilaksanakan dengan menggunakan pendekatan klasikal dan pendekatan individual. Pendekatan klasikal berupa penyampaian materi dan pendekatan individual berupa pendampingan (Mustika et al., 2018; Sadikin et al., 2021). Prosedur pelaksanaan kegiatan pengabdian dapat di gambarkan sebagai berikut.

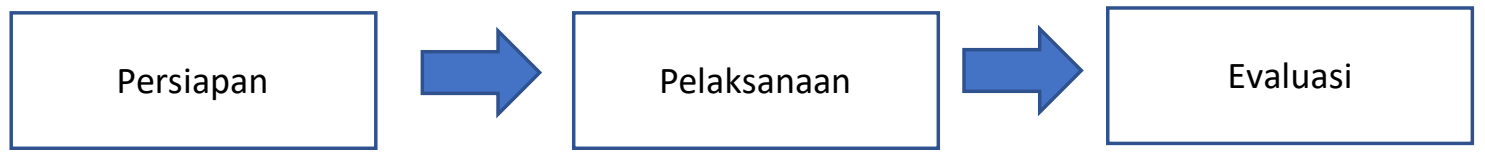

Gambar 1. Prosedur kegiatan pengabdian

Pada Gambar dapat diamati bahwa prosedur kegiatan pengabdian terdiri dari tiga tahapan utama yaitu persiapan, pelaksanaan, dan evaluasi. Secara lebih rinci uraian kegiatan pada pengabdian ini adalah :

1. Memberi penjelasan konseptual tentang penyusunan artikel ilmiah

2. Memberi panduan dan menjelaskan pedoman penyusunan artikel ilmiah

3. Membimbing praktik penyusunan artikel ilmiah dengan berpanduan pada template yang diberikan serta laporan penelitian yang peserta miliki.

4. Pendampingan peserta oleh dosen kepada guru selama kegiatan penyusunan artikel ilmiah.

5. Pelaksanaan penilaian terhadap artikel ilmiah yang dibuat untuk mengetahui pemahaman guru dalam membuat artikel setelah diberikan pelatihan.

\section{HASIL DAN PEMBAHASAN}

Pelaksanaan kegiatan pengabdian dimulai dengan melakukan observasi lapangan terlebih dahulu di SDN 193 Pekanbaru. Observasi lapangan juga bertujuan untuk untuk meminta izin serta mengkomunikasikan tahapan kegiatan pada pihak sekolah. Setelah observasi lapangan dilakukan selanjutnya, berdasarkan kesepakatan mitra SDN 193 Pekanbaru dengan tim pengabdian maka kegiatan pengabdian dilaksanakan pada tanggal 10 Januari 2020 bertempat di ruangan majelis guru SDN 193 Pekanbaru. Hasil dari pelaksanaan kegiatan pengabdian dapat diuraikan sebagai berikut :

1. Tahap Persiapan

Pada tahap persiapan, tim pengabdian mempersiapkan segala persiapa yang berkaitan dengan kegiatan yang dilaksanakan. Beberapa hal utama yang 
dipersiapkan adalah materi presentasi, pedoman penyusunan artikel ilmiah, pengaturan tugas setiap anggota tim, kelengkapan alat dan bahan penunjang kegiatan.

2. Tahap Pelaksanaan

Pada tahap pelaksanaan, disampaikan segala informasi berkaitan dengan penyusunan artikel ilmiah. Dokumentasi pelaksanaan dapat diamati pada Gambar 2.

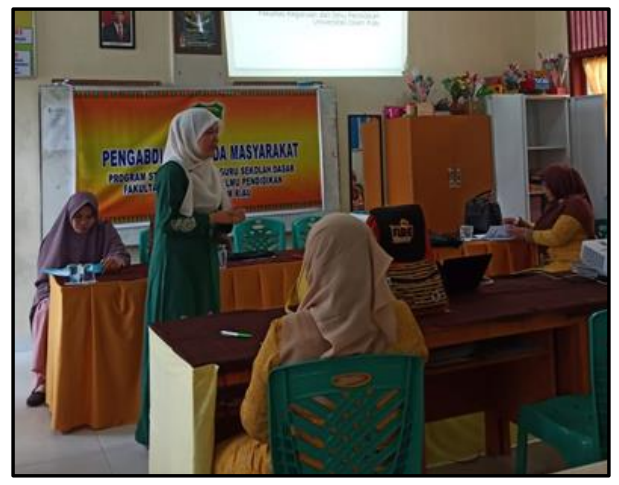

Gambar 2. Penyampaian materi

Pada Gambar 1 dapat dilihat penyampaian materi dilakukan oleh ketua pengabdian. Informasi yang berkaitan dengan artikel ilmiah disampaikan dengan maksud memberi pemahaman dasar tentang penyusunan artikel ilmiah pada peserta pengabdian. Selanjutnya setelah materi disampaikan, anggota pengabdian membantu membagikan pedoman penyusunan artikel ilmiah pada peserta pengabdian. Peserta pengabdian yang mempunyai laporan penelitian berupa penelitian tindakan kelas dapat mulai menyusun artikel ilmiah seperti panduan yang diberikan. Dokumentasi pelaksanaan kegiatan dapat diamati pada Gambar 3.

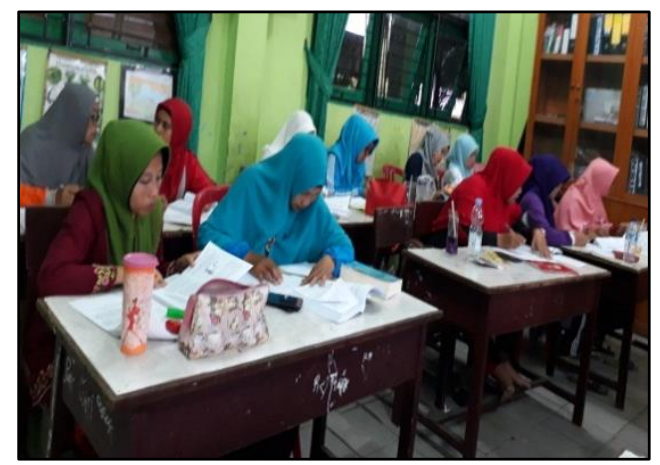

Gambar 3. Peserta berlatih menyusun artikel ilmiah

Pada Gambar 3 peserta berlatih menyusun artikel ilmiah berdasarkan laporan penelitian berupa Penelitian Tindakan Kelas yang dimiliki serta panduan template artikel ilmiah yang telah disediakan. Selama pelaksanaan kegiatan ini peserta pengabdian tampak antusias mencoba menulis sendiri walau sebagian dari peserta masih mengalami kesulitan terutama dalam bagian pengutipan. Bagi peserta 
pengabdian yang mengalami kesulitan dapat langsung bertanya pada tim pengabdian.

3. Tahap Evaluasi

Pada tahap evaluasi, tim pengabdian dibagi untuk memeriksa hasil dari penyusunan artikel ilmiah yang telah dibuat peserta pengabdian. Hasil evaluasi kemudian dijadikan sebagai bahan diskusi lanjutan bersama peserta pengabdian untuk mencari tahu letak kesalahan dan kekurangan artikel yang telah dibuat. Pada kesempatan ini tim pengabdian pun menawarkan bagi peserta yang berminat untuk mempublikasikan artikel yang telah dibuat maka tim pengabdian akan membantu menemukan sarana publikasi yang tepat.

Pelaksanaan kegiatan pengabdian ini dapat dikatakan berjalan dengan baik. Peserta pengabdian menunjukkan antusiasme dan bersikap partisipatif selama kegiatan dilaksanakan. Produk yang dihasilkan dari kegiatan pengabdian ini adalah berupa draft artikel ilmiah yang disusun berdasarkan template yang disiapkan. Hasil akhir dari pelaksanaan pelatihan juga mendapat tanggapan positif dari kepala sekolah dan peserta pengabdian, yang mana kepala sekolah menyatakan pelatihan memang perlu diadakan agar guru-guru semakin termotivasi untuk menulis karya ilmiah. Harapannya, kegiatan pelatihan ini dapat dilakukan secara berkesinambungan dengan materi yang lebih beragam serta bermanfaat untuk pengembangan karir dan profesional guru

\section{SIMPULAN}

Kegiatan pengabdian kepada masyarakat ditujukan pada guru sekolah dasar dengan melakukan pelatihan penyusunan artikel ilmiah. Kegiatan yang dilaksanakan telah berjalan dengan baik mulai dari tahap persiapan hingga tahap evaluasi. Kegiatan ini membantu menambah pengetahuan dan pemahaman guru sekolah dasar tentang artikel ilmiah, selain itu guru dapat berlatih menyusun artikel ilmiah berdasarkan laporan penelitian yang dimiliki dan template artikel ilmiah yang telah disiapkan. Selama pelaksanaan kegiatan, peserta menunjukkan antusiasme dan berharap kegiatan pengabdian dapat dilaksanakan secara berkelanjutan dengan penyampaian materi yang berbeda.

\section{UCAPAN TERIMA KASIH}

Ucapan terimakasih disampaikan pada LPPM Universitas Islam Riau yang telah mendanai pelaksanaan kegiatan pengabdian dan pihak SDN 193 Pekanbaru yang telah memberikan izin serta membantu menyediakan tempat pelaksanaan kegiatan. Selain itu, disampaikan terimakasih kepada pihak-pihak yang telah banyak membantu sehingga kegiatan pengabdian ini dapat berjalan dengan baik.

\section{REKOMENDASI}

Pada pelaksanaan kegiatan pengabdian ini, kegiatan hanya dilaksanakan terbatas pada membimbing guru menyusun artikel ilmiah menggunakan template yang ditentukan. Ini dikarenakan terbatasnya waktu dalam pelaksanaan kegiatan. Direkomendasikan untuk 
kegiatan pengabdian berikutnya mengambil tema yang sejalan yaitu tentang bimbingan penyusunan artikel hingga dapat dipublikasikan pada jurnal-jurnal nasional.

\section{REFERENSI}

Abdillah. (2012). Bahan dan Metode Artikel Ilmiah (Vol. 4). Universitas Binadarma.

Annisa, M., \& Hamid, H. (2016). Pengembangan Profesionalisme Guru Melalui Pelatihan Penyusunan Karya Tulis Ilmiah di Wilayah Pedalaman. Jurnal Widya Laksana, 5(2), 8184.

Arta, K. S. (2019). Pelatihan Penulisan Artikel Untuk Publikasi Di Jurnal Ilmiah Untuk Meningkatkan Profesionalisme Bagi Guru-Guru Di Kecamatan Kubutambahan Kabupaten Buleleng. Acarya Pustaka, 5(2), 17. https://doi.org/10.23887/ap.v5i2.17412

Benardi, A. I., \& Putro, S. (2019). Pelatihan Penulisan Publikasi Jurnal Ilmiah Terakreditasi Nasional Bagi Guru di MGMP. Jurnal Panjar, 1(1).

Cahyo, E., Taufik Nurhadi, Luluk Isani Kulup, Henricus Supriyanto, \& Mimas Ardhianti5. (2021). Pelatihan Penulisan Artikel Hasil Penelitian Tindakan Kelas Guru SMPN N 1 Gresik. Jurnal Penamas Adi Buana, 4(2), 124-128. https://doi.org/10.36456/penamas.vol4.no2.a2854

Gunawan, I. (2014). Metode Penelitian Kualitatif. Bumi Aksara.

Hidayah, R., Maharani, D. K., \& Muchlis. (2020). Pelatihan Penulisan Artikel Ilmiah Berbasis Penelitian Tindakan Kelas (PTK) Bagi Guru Kimia SMA Di MGMP Kimia SMA Kabupaten Kediri. Jurnal ABDI, 5(2), 107-110.

Ismail, \& Elihami. (2019). Pelatihan Penyusunan Artikel Publikasi Ilmiah bagi Mahasiswa Perguruan Tinggi STKIP Muhammadiyah Enrekang. Maspul Journal of Community Empowerment, 1(1), 12-20.

Mustika, D., Putra, E. D., \& Febriyanti, D. A. (2018). Pelatihan Penyusunan RPP Tematik bagi Guru Sekolah Dasar di Kecamatan Siak Hulu Kabupaten Kampar. Jurnal Masyarakat Mandiri, 2(2), 183-188.

Nurgiansah, T. H. (2020). Pelatihan Penulisan Artikel Ilmiah Bagi Mahasiswa PPKn Universitas PGRI Yogyakarta. 1(1), 16-23.

Prabawati, M. N., \& Muslim, S. R. (2020). Pendampingan Penulisan Artikel Ilmiah Bagi Guru Matematika Sekolah Menengah Pertama Wilayah Sukaraja Kabupaten Tasikmalaya Mega. Abdimas Umtas, 3(1), 207-212.

Sadikin, A., Johari, A., Siburian, J., Wicaksana, E. J., \& Natalia, D. (2021). Pelatihan Mendeley untuk Menunjang Karya Ilmiah Guru-Guru SMAN Titian Teras H . Abdurrahman Sayoeti. Solma, 10(01), 1-7.

Setianingsih, T., Qomariyah, S. S., Ariani, S., \& Suhaili, M. (2020). Pelatihan Penulisan Karya Tulis bagi Guru SMA Hang Tuah 3 Mataram. Undikma, 1(1), 18-21.

Suyono, Srinarwati, D. R., Arsana, I. W., Lestari, B. B., \& Arsana, I. M. (2021). Teknik Penulisan Karya Tulis Ilmiah: PPM Bagi Guru PKn di Kabupaten Probolinggo. Kanigara, 1(1), 91-96. https://doi.org/10.36456/kanigara.v1i1.3232

Yanti, G., Megasari, S. W., Sipil, S. T., Teknik, F., \& Kuning, U. L. (2020). Pelatihan Penulisan Artikel untuk Publikasi E-Jurnal Bagi Researcher Club. Dinamisia: Jurnal Pengabdian Kepada Masyarakat, 4(3), 461-469. https://doi.org/https://doi.org/10.31849/dinamisia.v4i3.4107 